\title{
Revista Brasileira de
}

\section{PUBLICAÇÕES NOVAS/ NEW PUBLICATIONS}

\section{ANTICONCEPÇÃO}

HATCIDER, R. A., RINEHART, W., BLACKBURN,R., GELLER, J. S., SIHELTON, J. D. Lo Esencial dela Tecnologia Anticonceptiva. Baltimore: Programa de Información en Población de Johns Hopkins del Centro para Programas de Comunicación, 2002. 339p.

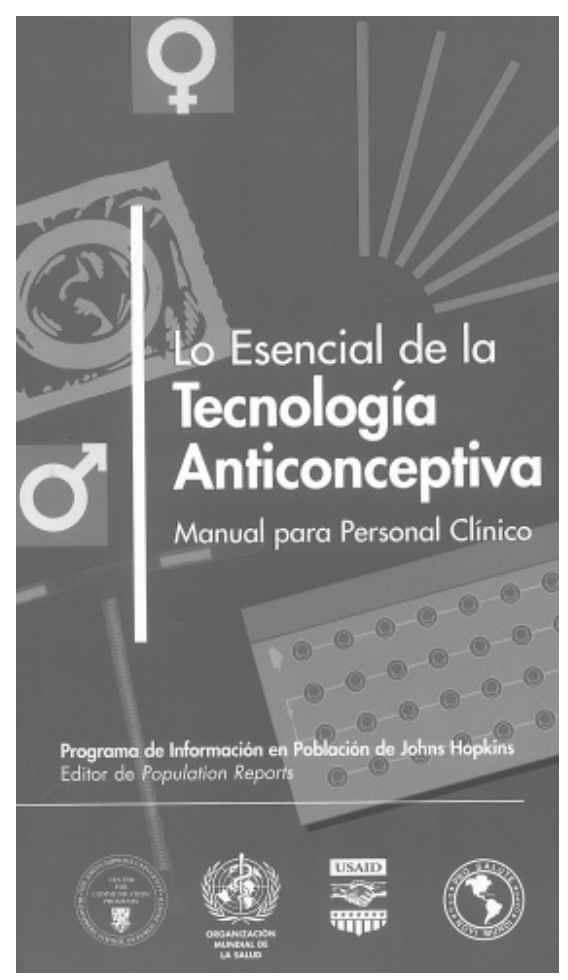

Este manual, dedicado a profissionais de saúde envolvidos no planejamento familiar, contou com o apoio da GHIPOPICNff, Global, USAID, OPS e OMS. O manual é fluto do esforço do Dr. Robert A. Hatcher da Facultad de Medicina de Ia Universidad Emory, e membros responsáveis pela publicação de Population Reports, revista produzida pelo Programa de Información en Población del Centro para ProgIranias de Comunicación de Johns Hopkins, que é par- te da Facultad de Ia Salud Publica da Universidad Johns Hopkins. A obra, constituída de 16 capítulos, considera o planejamento familiar um direito humano, essencial à dignidade humana. O capítulo 1 ensina como usar o livro. O capítulo 2 explica como o planejamento familiar ajuda a todos. $\mathrm{O}$ capítulo 3 explica o que é aconselhamento, seus princípios, temas abordados e etapas a serem seguidas. O capítulo 4 contém informações importantes para o profissional encarregado do planejamento familiar, entre elas, as várias condições de saúde e o método de planejamento familiar escolhido, assim como a eficácia de cada método. Nos capítulos 5 a 15 são enfocados os vários métodos anticoncepcionais que são enumerados na contracapa. Cada um desses capítulos traz uma breve descrição do método, alguns nomes comuns, o mecanismo de ação, as vantagens e desvantagens, os critérios de elegibilidade, quando começar a usar, como usar e resolução de problemas. Assim, os capítulos abordam, respectivamente, os anticoncepcionais orais combinados de dose baixa, os anticoncepcionais orais só com progestagênio, os anticoncepcionais injetáveis com acetato de medroxiprogesterona de depósito (DNWA), os implantes de Norplant (cápsulas plásticas de progestogênio), a esterilização feminina, a vasectomia, o preservativo masculino, os dispositivos intrauterinos (DIU), os métodos vaginais (espermicidas, diaftagma e preservativo feminino), os métodos naturais, incluindo a abstinência periódica (método da temperatura basg e método do calendário) e método da lactância-amenorréia. O capítulo 16 aborda as enfermidades de transmissão sexual (incluindo a AIDS), fornecendo os sintomas, o tratamento e a relação com o planejamento familiar. No final, no apêndice, há uma tabela com os critérios da OMS para iniciar os métodos anticoncepcionais.

A obra constitui-se em instrumento importante de informações precisas e atualizadas das recomendações sobre normas e práticas do planejamento familiar, contribuindo para o atendimento de boa qualidade e de fácil acesso, que é a chave para o êxito do planejamento familiar, permitindo o uso deste por tempo e eficácia maiores.

Profa. Veni Maria Andres Felli

FCF/USP 